\title{
A Rare Case of Cedecea Davisae Bacteremia Presenting as Biliary Sepsis
}

\author{
Venkata Sowjanya Kanakadandi $^{1}$, Manbeer S. Sarao ${ }^{2}$, Jessica M. Cunningham ${ }^{1}$ \\ 1. Internal Medicine, University of Pittsburgh Medical Center Pinnacle, Harrisburg, USA 2. Internal Medicine, Griffin \\ Hospital, Derby, USA
}

Corresponding author: Manbeer S. Sarao, manbir.sarao@gmail.com

\begin{abstract}
Cedecea davisae is a gram-negative, non-sporulating motile rod-shaped bacteria of the Enterobacteriaceae family. It is an opportunistic pathogen in advanced-aged patients with many comorbid diseases and the immunosuppressed. To the best of our knowledge, only 12 cases of C. davisae bacteremia have been reported in the literature. Here we discuss the 13th case of C. davisae bacteremia, which is the first reported case presenting as biliary sepsis.
\end{abstract}

A 41-year-old female, on prednisone for minimal change disease, presented with nausea, vomiting, fever, and diarrhea. She had dry mucous membranes, scleral icterus, and elevated liver enzymes. Blood cultures revealed Cedecea davisae. She improved after management with broad-spectrum antibiotics.

Further studies are needed to understand its role in the mode of transmission, the spectrum of infection, and treatment options. There is a need for physicians to be cognizant of emerging pathogens and address their antibiotic resistance profiles.

Received 07/06/2019

Review began $07 / 08 / 2019$

Review ended 07/28/2019

Published 08/01/2019

\section{(c) Copyright 2019}

Kanakadandi et al. This is an open access article distributed under the terms of the Creative Commons Attribution License CC-BY 3.0., which permits unrestricted use, distribution, and reproduction in any medium, provided the original author and source are credited.
Categories: Internal Medicine, Gastroenterology, Infectious Disease

Keywords: cedecea davisae, biliary sepsis, immunocompromised, gram-negative

\section{Introduction}

Cedecea davisae (C. davisae), a member of the Enterobacteriaceae family, is a gram-negative, oxidase negative, lipase positive, non-sporulating motile rod-shaped bacteria [1]. It has been isolated from various clinical specimens including sputum (the most common source), urine, cutaneous and oral ulcers, scrotal abscesses, peritoneal dialysis fluid, and the gallbladder. It is an opportunistic pathogen in advanced-aged patients with many comorbid diseases and the immunosuppressed. The combination of AmpC production and porin deficiency in the cell wall contributes to its multidrug resistance [2]. It possesses plasmid carrying multidrug resistance genes, through which it can transfer its genetic materials to other susceptible bacteria in the same ecosystem [3]. To the best of our knowledge, only 12 cases of $C$. davisae bacteremia have been reported in the literature. Here we discuss the 13th case of $C$. davisae bacteremia, which is the first reported case presenting as biliary sepsis.

\section{Case Presentation}

A 41-year-old female, with a past medical history of minimal change disease, diagnosed two years ago, being treated with a tapering dose of prednisone (on $7.5 \mathrm{mg}$ daily at the time of admission) and biliary cancer status post percutaneous cholecystostomy drain placed 10 days prior, presented to the emergency department with nausea, vomiting, fever, and diarrhea of one-day duration. This was associated with a decreased output from the cholecystostomy drain.

Six weeks prior to this presentation, the patient had routine monthly blood work done by her nephrologist and was noted to have bilirubin in her urine. Her liver function tests were then ordered which were abnormal and a right upper quadrant ultrasound showed moderate to marked diffuse intrahepatic bile duct dilation with a suspected obstructing mass at the porta hepatis. Outpatient work-up including alpha-1 antitrypsin, ceruloplasmin, antimitochondrial antibody, Hepatitis B, Hepatitis C, cytomegalovirus, iron, and ferritin were all negative or within the normal range. Her antinuclear antibody titer was at 1:40. Given concern for an obstructing mass, the patient was referred to the emergency room for expedited endoscopic retrograde cholangiopancreatography (ERCP). A computed tomography (CT) of the abdomen was done and it confirmed a mass at the hepatic hilum with associated biliary obstruction.

The patient had ERCP where she was found to have a high-grade stricture at the hepatic bifurcation. A sample was collected and sent for cytology and a stent was placed within the left intrahepatic biliary tree. The cytology from the ERCP returned as rare atypical cells with no malignant cells. A follow-up magnetic resonance imaging (MRI) of the abdomen was ordered and again showed a solid mass at the porta hepatis. A CT-guided liver biopsy was performed and pathology was pending when the patient was referred to 
interventional radiology due to continued significant hyperbilirubinemia. The patient underwent a cholangiogram and after some difficulty passing a wire, an internal/external biliary drainage catheter was placed. The drain was putting out 500-600 ml per day of bile.

She was undergoing prep for colonoscopy to rule out a colonic source of malignancy when her biliary output began to decrease and she developed the symptoms which prompted her return to the emergency room.

In the emergency room, she appeared to be in distress, with a temperature of $99.3^{\circ} \mathrm{F}$, heart rate $142 / \mathrm{min}$, blood pressure $92 / 52 \mathrm{mmHg}$, respiratory rate 18/min and SpO2 98\% on room air. Her physical exam was significant for dry mucous membranes, scleral icterus, and a non-tender abdomen. Her laboratory investigations revealed sodium $133 \mathrm{mmol} / \mathrm{L}$, alkaline phosphatase $486 \mathrm{U} / \mathrm{L}$, aspartate transaminase $122 \mathrm{U} / \mathrm{L}$, alanine transaminase $212 \mathrm{U} / \mathrm{L}$, bilirubin $14.6 \mathrm{mg} / \mathrm{dL}$ (direct bilirubin $8.0 \mathrm{mg} / \mathrm{dL}$ ), and international normalized ratio 1.4. Management, according to the sepsis protocol, included intravenous (IV) fluids and the broad-spectrum antibiotics cefepime and vancomycin. A contrast-enhanced CT of the abdomen confirmed good biliary drain position. It also revealed vicarious excretion of bile and an enlarged periportal lymph node. Metronidazole was added to the treatment regimen. The patient received aggressive fluid resuscitation in the intensive care unit, with a total of $8.5 \mathrm{~L}$ of IV fluid being given over 30 hours. Initial blood cultures grew gram-negative rods, so Vancomycin was discontinued and infectious disease was

consulted. Eventually, blood cultures revealed Cedecea davisae identified on micro scan and crystal identification, resistant to ampicillin, ceftriaxone, and cefuroxime. Repeat blood cultures were negative at 48 hours. Infectious disease recommended transitioning to Ciprofloxacin $500 \mathrm{mg}$ orally every 12 hours and Metronidazole $500 \mathrm{mg}$ orally every 8 hours to complete a 14-day course. At the time of discharge, she was feeling well and her vital signs were all within normal limits.

\section{Discussion}

The genus Cedecea is a member of the family Enterobacteriaceae. Its name comes from the abbreviation "CDC," for the Centers for Disease Control and Prevention (CDC), where the initial group of isolates, “Enteric Group 15,” were discovered [4]. The genus Cedecea consists of six species. Three of these, C. davisae, Cedecea lapagei, and Cedecea neteri (formerly known as Cedecea species 4 or Cedecea species 002 ) have been fully identified and named after the American bacteriologist Dr. Betty R. Davis, the British bacteriologist Dr. Stephen P. Lapage and the American physician-microbiologist Dr. Erwin Neter respectively, who all have made significant contributions to the Enterobacteriaceae family [5]. The remaining three unnamed species are Cedecea species 001 (also known as Cedecea species 3), Cedecea species 012 (also known as Cedecea species 5), and Cedecea species 6.

The species was first identified in 1977 by a group of microbiologists who classified it under the genus of Enterobacteriaceae. The organism was found to be lipase positive, DNase and gelatin negative with resistance to colistin and cephalothin [6]. In 1981, Cedecea was designated as a separate genus of the Enterobacteriaceae family as it was phenotypically distinct from the other members of the family and given its name.

There have been very few cases of reported Cedecea infections and only 12 C. davisae infections (see table) since its discovery in 1977. Sputum, gall bladder, skin wounds, and abscesses are some of the sources the species has been isolated from. However, the natural habitat of the organism is yet to be determined. Infections such as pneumonia, urinary tract infection, and sepsis, that have been documented in the past have been rare and were largely caused by the lapagei and neteri species. Cedecea davisae has been isolated in reported cases of bacteremia, which also have been very few.

One of the first known cases of C. davisae bacteremia was reported by Perkins et al. in 1986, who isolated the organism from sputum, central venous and Swan-Ganz catheters, along with Staphylococcus epidermidis. The patient did have sputum positivity, but no pneumonia; hence, there was a consideration given that the infection was acquired from the patient's own flora. In most cases, patients that did have infections with Cedecea were found to be immunocompromised with uncontrolled diabetes mellitus, renal transplant, chronic kidney stage $\mathrm{V}$, chronic bronchitis or having an underlying malignancy. Based on previously reported cases, there also appears to be an association with the presence of catheters, from which the organism has been isolated. Our current knowledge on this organism has only been from the few previously reported cases, which indicate an opportunistic nature to the infections caused by it. Further studies are needed to fully explore the pathogenicity of this organism.

Though infections with C. davisae or the genus Cedecea in itself are rare, treating them is a challenge due to their broad-spectrum antibiotic resistance. Apart from resistance to colistin and cephalothin, previously described cases reported also report microbial resistance to, cefuroxime, ceftazidime, ampicillin, tetracycline, cefoxitin, piperacillin, nitrofurantoin, ciprofloxacin, several aminoglycosides, and thirdgeneration cephalosporins. The combination of AmpC production and porin deficiency in the cell wall contributes to the multidrug resistance.

Our case describes the 13 th case of $\mathrm{C}$. davisae bacteremia and adds to the limited literature available. To the 
best of our knowledge, this is the first case of $C$. davisae bacteremia presenting as biliary sepsis. As seen in Table 1, the infection could have various presentations.

\begin{tabular}{|c|c|c|c|c|}
\hline Year & Age & Gender & Comorbidities & Site \\
\hline \multirow{2}{*}{$1981[7]$} & 65 & $\mathrm{~F}$ & DM, CHF, HTN & Sputum \\
\hline & 76 & M & HTN, arteriosclerotic heart disease & Sputum \\
\hline 1983 [8] & 50 & M & HTN, CHF, alcoholic hepatitis & Scrotal abscess \\
\hline $1986[6]$ & 70 & $\mathrm{~F}$ & Heart disease, bronchitis, COPD & Blood \\
\hline 2008 [4] & 67 & M & DM & Blood, Leg ulcer \\
\hline 2010 [9] & 42 & M & s/p Renal transplantation, DM, HTN & Oral ulcer \\
\hline 2011 [10] & 52 & M & AML, Clostridium difficile colitis & Blood \\
\hline \multirow{2}{*}{$2012[11-$} & 54 & M & Sigmoid colon cancer & Blood \\
\hline & 20 & $\mathrm{~F}$ & CF, DM & Sputum \\
\hline 2013 [1] & 77 & $\mathrm{~F}$ & DM, HTN, CKD & Blood and permacath catheter tip \\
\hline 2015 [13] & 57 & $\mathrm{~F}$ & Atrophic rhinitis with mucocele & Mucocele \\
\hline 2018 [5] & 76 & $\mathrm{M}$ & UTI s/p prostatectomy & Urine \\
\hline
\end{tabular}

\section{TABLE 1: Cases of Cedecea davisae in Literature}

DM: diabetes Mellitus; CHF: congestive heart failure; HTN: hypertension; COPD: chronic obstructive pulmonary disease; AML: acute myeloid leukemia; CF: cystic fibrosis; CKD: chronic kidney disease; UTI: urinary tract infection

\section{Conclusions}

As the species has an inherent resistance to a broad spectrum of antibiotics, management is challenging, particularly in immunocompromised individuals. Hence, further studies are needed to understand $C$. davisae's role in the mode of transmission, the spectrum of infection and treatment options.

\section{Additional Information \\ Disclosures}

Human subjects: Consent was obtained by all participants in this study. Conflicts of interest: In compliance with the ICMJE uniform disclosure form, all authors declare the following: Payment/services info: All authors have declared that no financial support was received from any organization for the submitted work. Financial relationships: All authors have declared that they have no financial relationships at present or within the previous three years with any organizations that might have an interest in the submitted work. Other relationships: All authors have declared that there are no other relationships or activities that could appear to have influenced the submitted work.

\section{References}

1. Peretz A, Simsolo C, Farber E, Roth A, Brodsky D, Nakhoul F: A rare bacteremia caused by Cedecea davisae in patient with chronic renal disease. Am J Case Rep. 2013, 14:216-218. 10.12659/AJCR.889285

2. Ammenouche N, Dupont H, Mammeri H: Characterization of a novel AmpC $\beta$-Lactamase produced by a carbapenem-resistant Cedecea davisae clinical isolate. Antimicrob Agents Chemother. 2014, 58:6942-6945. 10.1128/AAC.03237-14

3. Agbonlahor D, Ehiaghe J, Eremwanarue O, et al.: A primal incrimination of Cedecea davisae with postprostatectomy urinary tract infection in Nigeria. Int J Biol Chem Sci. 2018, 12:676-688. 10.4314/ijbcs.v12i2.6

4. Janda JM, Abbott SL: Uncommon enterobacterial genera associated with clinical specimens . The Enterobacteria. ASM Press, Washington; 2006. 357-359. 10.1128/9781555817541

5. Dalamaga M, Pantelaki M, Karmaniolas K, Matekovits A, Daskalopoulou K: Leg ulcer and bacteremia due to Cedecea davisae. Eur J Dermatol. 2008, 18:204-205.

6. Perkins SR, Beckett TA, Bump CM: Cedecea davisae bacteremia. J Clin Microbiol. 1986, 24:675-676.

7. Bae BH, Sureka SB, Ajamy JA: Enteric group 15 (Enterobacteriaceae) associated with pneumonia . J Clin Microbiol. 1981, 14:596-597.

8. Bae BH, Sureka SB: Cedecea davisae isolated from scrotal abscess. J Urol. 1983, 130:148-149. 10.1016/S00225347(17)51004-6 


\section{Cureus}

9. Mawardi H, Pavlakis M, Mandelbrot D, Woo SB: Sirolimus oral ulcer with Cedecea davisae superinfection. Transpl Infect Dis. 2010, 12:446-450. 10.1111/j.1399-3062.2010.00514.x

10. Abate G, Qureshi S, Mazumder SA: Cedecea davisae bacteremia in a neutropenic patient with acute myeloid leukemia. J Infect. 2011, 63:83-85. 10.1016/j.jinf.2011.04.007

11. Akinosoglou K, Perperis A, Siagris D, Goutou P, Spiliopoulou I, Gogos CA, Marangos M: Bacteraemia due to Cedecea davisae in a patient with sigmoid colon cancer: a case report and brief review of the literature. Diagn Microbiol Infect Dis. 2012, 74:303-306. 10.1016/j.diagmicrobio.2012.06.019

12. Ismaael TG, Zamora EM, Khasawneh FA: Cedecea davisae's role in a polymicrobial lung infection in a cystic fibrosis patient. Case Rep Infect Dis. 2012, 2012:176864. 10.1155/2012/176864

13. Bayir O, Yildirim GA, Saylam G, Yuksel E, Ozdek A, Korkmaz MH: Atrophic rhinitis caused by Cedecea davisae with accompanying mucocele. Kulak Burun Bogaz Ihtis Derg. 2015, 25:249-253. 10.5606/kbbihtisas.2015.93265 